\title{
ACREDITACIÓN DE ALTA CALIDAD FACULTAD DE INSTRUMENTACIÓN QUIRÚRGICA
}

Ivonne Acuña L.*

Esta es una valiosa oportunidad para hacer honor a la Facultad de Instrumentación Quirúrgica, que vive una de las mejores épocas de su historia en su larga y fructífera labor de sesenta y tres años (1951-2014), pionera en esta área de la salud, que ha construido paso a paso cada una de sus importantes realizaciones, ha diseñado planes, procedimientos y estrategias llevando de la mano la exigencia en la formación profesional de los estudiantes.

El devenir histórico de la Facultad de Instrumentación Quirúrgica encuentra su fortaleza y su eje en la producción y actualización permanente del conocimiento a través de cada uno de los momentos de su labor formativa, académica y pedagógica. Es aquí donde se inspira y se justifica su proyecto pedagógico para garantizar el enriquecimiento del pensamiento a través de todas las áreas y del entorno académico.

Estamos seguros que este es el camino que le da identidad a nuestra facultad para formar y preparar a los futuros egresados con herramientas y capacidades para proyectarlos exitosamente y que puedan desempeñarse con idoneidad y acierto en cualquier ámbito de su vida personal, profesional y familiar, en el contex to nacional y aún más allá del espacio colombiano.

La tradición del programa ha sido formar profesionales integrales reconocidos por la comunidad. Los laboratorios con tecnología de punta permiten fundamentar el proceso de enseñanza-aprendizaje de manera satisfactoria. Los escenarios de práctica en los dos hospitales universitarios propios, aseguran que los estudiantes puedan acceder a los diferentes niveles de complejidad quirúrgica. La producción multimedial, la formación en investigación como proceso transversal del currículo, los desempeños y las prácticas de excelencia académica, el ejercicio docente de la más alta calidad y la fortaleza de los procesos administrativos, fueron componentes decisivos para validar los estándares y parámetros exigidos por el Ministerio de Educación Nacional a través del concepto emitido por el Consejo Nacional de Acreditación CNA, por medio de la resolución No. 17185 del 27 de noviembre de 2013, la cual otorga al programa de Instrumentación Quirúrgica la acreditación de alta calidad, logro de gran magnitud, impacto y transcendencia que constituye el hito más importante en la historia actual de la Facultad.

Este riguroso proceso de acreditación exige un trabajo continuo de mejora realizando sistemáticamente verificaciones y validaciones a través de los procesos de autoevaluación con estándares externos, para certificar la calidad de los planes de estudio. Los desempeños de las diferentes promociones de egresados ubican en una meritoria posición de vanguardia a la Facultad.

La Fundación Universitaria de Ciencias de la Salud ha sido coherente en su quehacer académico y profesional, con lo consignado en la misión, visión y propósitos formativos, componentes fundamentales para diseñar e implementar planes de mejora continua que permitirán mantener a la facultad a la altura de las exigencias del mundo actual.

Agradecemos a toda la comunidad universitaria la dedicación y estimulo permanente para lograr este reconocimiento de calidad académica.

Decana Facultad de Instrumentación Quirúrgica 